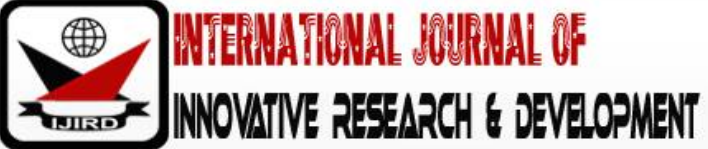

ISSN 2278 - 0211 (Online)

\section{Exercise Reflective Listening and Nonverbal Communication}

\author{
Ningxin Li \\ Ph. D. Student, Department of Conflict Resolution, \\ Nova Southeastern University, USA
}

\begin{abstract}
:
People express their emotions every day and often communicate with their parents and friends frequently. Exchanging ideas and sharing conversation are essential when people interact with each other. When a person talks to others to present himself/ herself, this person might hope to impress others. The author will explain how to improve communication ability and illustrate why people need to practice their reflective listening ability. Regular emotional exchange and holding positive attitude during a conversation will help to stimulate people's ability of maintaining a good relationship. The author will provide guidance for people and explain the importance of showing respect, building trust, and active cooperation. This paper will provide an understanding of using body language, such as gestures, facial expressions, and voice paralanguage, as well as explaining nonverbal communication skills.
\end{abstract}

Keywords: Nonverbal communications, reflective listening, body language, win-win negotiation

\section{Introduction}

Emotional exchanges between people will affect their behaviors and learning efficiency. During the interaction of training and learning, both the trainer and the learner are equal participants (Stone, Patton, \& Heen, 1999). The trainer should show respect and understand the learners' characteristics and hold a positive attitude for stimulating the learners' ability of communication. The learner needs to show respect, trust, and cooperate with the trainer through continuous learning and participating. After practicing, people will learn how to reach an agreement during a dispute, and use their body language, such as gestures, facial expressions, and voice paralanguage to effectively communicate with others (Duncan, 2002).A trainer can show the learner appropriate body language and teach the learner how to carefully observe nonverbal communication. Also, people can practice communication ability by focusing on reading for an hour every day. They can read 60 English words at one time to exercise their minds and memories. The process of practicing communication will improve their outsight and motivate intrinsic energy.

\section{Team Training}

Regular team training and role play are important for effective listening and communication. People should understand the meaning of "teamwork" and everyone should actively participate in discussion in order to develop interpersonal skills (Katz, Lawyer, \& Sweedler, 2011). When communicating, people should try to be confident and use fluent language to express ideas. They should listen carefully in order to remember important information and clarify ideas when another person has difficulty understanding them.

In interpersonal communication, individuals can use body language, as well as change tone and voice to express ideas. The use of body language includes facial expressions, eye contact, and body posture (Goleman, 2004). Body movements can provide a visual impression and produce good communication effects (Goleman, 2004). People can be trained to understand the feelings of others and pay attention to eye contact. Eye contact can express a variety of emotional communications and show love, happiness, and other emotions. Accurately understanding subconscious minds will assist people in making decisions (Goleman, 2004). In addition, smiling is one of the facial expressions that is conducive to interpersonal communication (Goleman, 2004). People can show positive emotions, which will make others feel comfortable and as if they can approach other people.

\section{Mutual Motivation}

Understanding human emotional factors is important when managing interpersonal relations. Negative emotions include anger, anxiety, depression, envy, and fear, which will prevent people from maintaining long-term relationships (Hogan, 1999). Showing people positive emotions and bringing them happiness are important. People can try to control their negative emotions while talking to others (Wilmot \& Hocker, 2014). Negative words and emotions will lead the listeners to feel distant, which then will close a conversation. However, positive emotions, such as love, hope, sympathy, loyalty, and joy will delight others and make them feel comfortable and be happy to continue a conversation (Long, 1996). Also, accepting people's strengths and weaknesses is important. Showing acceptance to others will strengthen other 
people's confidence to communicate (Long, 1996). People should also show love and care for others in order to maintain a good relationship.

Considering cultural factors when communicating with other people is essential. People should understand and respect other people's values, cultures, and languages (Katz, Lawyer, \& Sweedler, 2011). Also, considering other people's needs and seeking common interests is important in interpersonal negotiation (Katz, Lawyer, \& Sweedler, 2011). People can create new ideas and make solutions together. To distinguish the problems and interests of other people, they can keep their emotions stable, and try to establish a harmonious atmosphere in group discussions (Katz, Lawyer, \& Sweedler, 2011).

A win-win negotiation is an outcome of reaching arrangements representing mutual gains (Thompson, 2013).During a conversation, people should recognize the values of others' suggestions and consider the following questions: "What do the other people actually say to you?" and "What will be the impact on you?" Individuals should figure out other people's needs by understanding their intentions and positions (Thompson, 2013). It is recommended to find the root cause of a problem before addressing an issue.

Determining goals and being confident while speaking is important (Long, 1996). Listening carefully when other people are speaking will help in training reflective listening ability (Long, 1996). The following questions can be considered for practicing reflective listening ability: Can you keep patient and wait when other people are expressing their ideas? Do you care about the consequences of wining or failing in an argument? Do you chime in quickly and show you are in a hurry? How can you find a solution that combines both your interests and other people's suggestions? Can you properly make pauses when giving a speech? In addition, individuals can show their understanding by acknowledging others' opinions. They can respond positively by saying, "I am happy with that," "I am interested in what you are saying," and "I agree with you."

\section{Conclusion}

Cooperation will help in leading a win-win situation, and a win-win strategy can be applied to manage disputes (Katz, Lawyer, \& Sweedler, 2011). A mutually acceptable solution can be discussed so that each person can meet their needs (Katz, Lawyer \& Sweedler, 2011). Making friends instead of solely focusing on a short-term win will initiate building a long-term relationship and will produce stable cooperation (Katz, Lawyer, \& Sweedler, 2011). It is important to improve reflective listening ability, carefully listen to each other, and show others that they are interested in the conversation. People can express views in a timely way and motivate others to communicate. A good communication skill will enhance people's way of thinking and gain more chance of mutual agreement in an interpersonal negotiation (Duncan, 2002). In addition, in communication practices, people should find creative ways to actively manage emotions, pay attention when other people speak, and flexibly use body language to express themselves. Effective listening and communication will lead to an effective and positive outcome, especially when people have different cultures and values.

\section{References}

i. Duncan, H. D. (2002). Communication and Social Order. NJ: Transaction Publishers.

ii. Goleman, D. (2004). What Makes a Leader. Harvard Business Review, Vol. 3.

iii. Hogan-Garcia, M. (1999). The Four Skills of Cultural Diversity Competence. CA: Wadsworth Publishing Company.

iv. Katz, N. H., Lawyer, J. W., \& Sweedler, M. K. (2011). Communication \& Conflict Resolution Skills. Dubuque: IA: Kendall Hunt.

v. Long, V. O. (1996). Communication Skills in Helping Relationships, A Framework for Facilitating Personal Growth. CA: Brook/Cole Publishing Company.

vi. Stone, D., Patton, B., \& Heen, S. (1999). Difficult Conversations. NY: Penguin Group.

vii. Thompson, L. (2013). The Truth About Negotiations. NJ: Pearson Education, Inc.

viii. Wilmot, W., \& Hocker, J. (2014). Interpersonal Conflict. NY: McGraw-Hill . 